\title{
VERSITA
}

\section{Poverty in Abundance: Is Corruption an Answer?}

\author{
Benjamin R. Barber ${ }^{{ }^{*}}$ \\ ${ }^{1}$ Center on Philanthropy and Civil Society, The Graduate Center, The City University of New York, 365 Fifth Avenue, Suite 5401, \\ New York, NY 10016-4309, United States of America.
}

KEYWORDS

Megacities

Corruption

Inequality

Poverty

Abundance

Urban equality

Global governance
ABSTRACT

With the challenges of inequality so embedded in the political and economic infrastructure and their origin at least in part associated with national and global forces outside and beyond the control of the city, remediation is extraordinarily difficult. Only with innovation and imagination is inequality likely to be touched. Only if we are willing to look at the informal as well as the formal economy, and ignore the common wisdom about corruption and squatting and hidden capital, are we likely to find some partial answers to the burdens under which the most progressive and prosperous cities labour. (Excerpt)

We almost always greet corruption as a pernicious feature of political life gone badly - especially in cities, where local politics seems to invite corrupt behaviour. Yet nearly fifty years ago, when I was a doctoral candidate at Harvard University, the great German-American constitutional theorist Carl J. Friedrich (who had helped write the post-war German constitution) observed rather casually in a lecture that corruption was to politics as arsenic was to human life: a poison likely to kill when introduced in a significant portion but a chemical critical to life itself when present in trace amounts. Ever since, I have been thinking about corruption, especially in the setting of unjust and inegalitarian regimes, where the economic and political infrastructure is already skewed and corrupt.

\footnotetext{
* Contact address: thepnyx@hotmail.com (B. R. Barber)
} 
Having now just completed a new book about the role of cities in global governance called If Mayors Ruled the World: Dysfunctional Nations, Rising Cities (2013), I have had the opportunity to re-evaluate Friedrich's argument in the specific context of global megacities already rife with inequality, cities that define Mike Davis's 'planet of slums' in his book about urban inequality with that title (2006).

If Mayors Rule the World confronts the plight of an interdependent world in which eighteenth century independent sovereign nation states often seem dysfunctional when it comes to international cooperation. It argues that the incapacity of states to cooperate in confronting climate change, immigration, predator global markets, crime, health pandemics or terrorism invites cities to play a new and influential role. That, if indeed, mayors and those they represent actually ruled the world - if only in a soft, bottom-up and consensual fashion - we might find ways to resolve democratically some of our global problems. It is certainly hard to imagine we can go on confronting a 21st century world of interdependent challenges while we are deploying pre-industrial nation-state solutions that have long since ceased to work.

The cities perspective changes our outlook on many things. Democracy can be more participatory, politicians more engaged, politics more focused on pragmatic solutions than divisive ideology. After all, mayors are homeboys and the equals of fellow citizens and neighbours. Through intercity associations like ICLEI and the C-40, cities have already demonstrated that can make real progress on curbing carbon emissions where states have been unable even to update the all too modest Kyoto Protocol at those annual meetings since Copenhagen marked by noble aspirations, hypocritical posturing and futile outcomes.

Cities and intercity cooperation represent then new beacons of hope in a tired world of flailing and dysfunctional nations. Yet cities have serious problems too, and poverty and inequality chief are among them. The cities' lens also refracts how we look at such problems. Richard Florida, for example, has argued that creativity and entrepreneurship are central to the urban identity and give cities a way to confront inequality. Here I want to 
pursue another perhaps more provocative argument: that in the perspective of cities suffering from structural inequality, even corruption may have its dialectical uses. In dire circumstances in developing world mega-cities whose mega-slums obstruct the path forward, corruption may even offer a perverse kind of opportunity to those otherwise without hope. What to the wealthy (whose own sins are invisible) what looks like vice, may to those caught in poverty appear as an exit strategy.

The point of this argument is not to embrace corruption or even tolerate it - for corruption is ultimately not only ruinous to democracy, but particularly corrosive to the prospects of poor people. They are its first victims. Nonetheless, they are also sometimes its beneficiaries in ways that help explicate the informal sides of city governance and the odd sympathy for corruption we can sometimes find in developing world narratives. Without offering anything resembling a blanket endorsement, I want here to suggest why corruption sometimes turns out to be the visible mirror image of injustices that in the dominant narrative are invisible.

The reality is that immigrants and newcomers may be benefited by inefficiency and even by mild workplace corruption, as the waves of immigrants a century ago in New York and Chicago and newcomers flocking to Sao Paulo and Mumbai today will attest. Corruption (even crime) undermines community and impedes democracy long term, but in the short run it can appear as an equalizer, a kind of crude fast track to proximate equality. For the poor, the short term may be the only 'term' there is. Disease, crime, malnutrition and class discrimination are likely to make the long term irrelevant.

To take equality and justice seriously then, we must always ask the question: corruption by whom? Crime against whom? In whose interests? Crime is in many instances a consequence of greed, selfishness and psychic disorder; but it can also reflect a twisted society in which criminality appears as the only way out for certain people on the margins. This is the lesson of John Gay's Beggars' Opera as well as of its more caustic rendering in Brecht's Three-Penny Opera. In the setting of a fair, equitable society in which equal 
opportunity belongs to all, both crime and corruption are unequivocal evils. But in a rigid, hierarchical, exploitative society in which exploitation and unfairness are built into a system, where upward mobility is a dubious proposition and bigotry and segregation close many of the conventional roads to integration and assimilation, those same vices become compensatory opportunities - not 'goods', but acceptable tactics in the struggle against systemic injustice.

In Brecht's towering play Mother Courage, one of her sons responds to a charge that he is exploiting army corruption to his own advantage by blurting out: 'Thank God they're corrupt. Corruption is the equivalent of God's mercy. As long as someone's on the take, you can buy a shorter sentence, so even the innocent have a shot at justice.'

Katherine Boo shows how poor residents of Mumbai live Brecht's cynical idealism. In her searing portrait of poverty in Mumbai called Beyond the Beautiful Forevers: Life, Death and Hope in a Mumbai Undercity (2012), Boo observes that 'for some people, corruption is one of the few opportunities that remain' (Boo interviewed by Leonard Lopate on WNYC, December 26, 2012). She tells the story of Mumbai children earning subsistence earnings from sorting and selling the garbage in which, quite literally, they live, and finding 'success' only in bending rules and exploiting corruption. 'In the West, and among some in the Indian elite,' Boo (2012) writes, 'this word corruption has purely negative connotations: it was seen as blocking India's modern, global ambitions. But for the poor of a country corruption was one of the genuine opportunities that remained.'

In Mexico City and Kabul, where police corruption directly endangers local residents, Boo's lessons drawn from the Annawadi slum near the Mumbai airport are not altogether convincing. Yet even in such cities (and Mumbai also suffers from police corruption in its approach to rape for example), corruption is more a testament to the failures of democracy in other domains - the persistence of segregation, the ignoring of poverty, the neglect of injustice. Those afflicted by the latter evils might be forgiven for seeing in the former some twisted form of a good, of democracy itself 
understood as a levelling down that lets them in the game, however much the 'rules' (calculated to disadvantage then) forbid it.

Ideally, of course reforming urban inequality in jobs and other domains calls for systemic if not revolutionary change. Yet as this discussion suggests, partial and contextualized solutions that work under the constrained circumstances of an unfair global society are a better bet for realists unwilling to wait for some distant 'forever'. Since the denizen of cities are not currently positioned to affect the global problems from which their local dilemmas arise, in part because urbanization is less voluntary in the developing world than in the West, exploiting corruption may seem the best option.

While historically, the West's big cities pulled people off the land and into the city with a siren song of economic opportunity and the seductive excitement of fresh lives of possibility, much of the rapid population growth in the developing world's megacities has been the result of people pushed off the land by unemployment and the kind of global market competition local agriculture can't combat. It is the negative profile of the rural economy rather than the positive profile of the city that sends people scrambling to the metropolis. Yet jobs are low-paying in an unstable and lackluster informal urban economy where their best hope is to find a position in the informal economy and a ghetto squat, and one day perhaps move from the informal to the formal urban economy, from squatting to owning a home. This is not simply naiveté. As one of Katherine Boo's subjects tells her, 'a decent life was the train that hadn't hit you, the slumlord you hadn't offended, the malaria you hadn't caught'. Still, in Mumbai and Lagos and Jakarta, the poor aspire to more than survival, and having expectations still makes sense. Unhappily, such expectations can lead the poor make war on one another; can allow racist Hindu parties such as Shiv Sena in cities like Mumbai to wage a campaign to 'purge Mumbai of migrants from India's poor northern states', above all, Muslims. Where there is something to fight over and a shred of hope that fighting makes a difference, such pale but seductive opportunities can contribute not only to mobility for the poor but 
to the astonishing growth of third world megacities that on their face seem bereft of either mobility or hope. In China for example, construction worker drawn from inland village China (where more than two thirds of China's population still live) have built colonies in the city that constitute a new and troubling form of transient urban ghetto, one without roots in any traditional neighbourhood and existing only as a temporarily employed male enclave possessing no discernible 'rights to the city'. Yet at the same time, millions of rural villagers have become significant sources of income for their destitute families and have helped redistribute income from the cities to the rural countryside. But such trade-offs are not viable as long-term solutions to inequality.

Poverty, injustice and segregation in every relevant urban sector in both the first world and third, remain major obstacles to urban equality and hence to the role of cities in nurturing democratic global governance. Too many of the urban advantages we celebrate, from creativity and culture to trade and diversity, have consequences that accrue to the middle and upper classes at the expense of the poor. What should be common city assets become zero sum games in which one (rich) man's redevelopment plan spells another (poor) man's loss of centre city housing; in which a wealthy woman's riverside playground condominium displaces a former manufacturing warehouse along with the poor women's sewing jobs the factory housed. In this setting city corruption is too often defined in ways that exempt white collar criminality (bank redlining to enforce segregation, for example, or bundling and reselling mortgage debt to distant investors insulated from responsibility to borrowers), even as they highlight activities of the poor that, while illegal, might ease their plight, however temporarily. Inequality comes in many forms, and - appropriately in this era of interdependence - these forms are intimately linked. Attack educational discrimination and it reappears as housing discrimination. Increase the number of working class jobs and inadequate transportation blocks the poor from getting to them. 
With the challenges of inequality so embedded in the political and economic infrastructure and their origin at least in part associated with national and global forces outside and beyond the control of the city, remediation is extraordinarily difficult. Only with innovation and imagination is inequality likely to be touched. Only if we are willing to look at the informal as well as the formal economy, and ignore the common wisdom about corruption and squatting and hidden capital, are we likely to find some partial answers to the burdens under which the most progressive and prosperous cities labour. Only if the underlying and intransigent realities of urban segregation in all its forms can be addressed are we likely to instigate mitigation successfully. It is in this context that we have to reexamine corruption and ask whether a blanket condemnation is possible; whether vice is not relative - always undesirable, but understandable sometimes in a context of still the greater evil of a wholly corrupt political and economic system.

\section{References:}

Barber, Benjamin R. 2013. If Mayors Ruled the World: Dysfunctional Nations, Rising Cities. New Haven: Yale University Press.

Boo, Katherine. 2012. Behind the Beautiful Forevers: Life, Death, and Hope in a Mumbai Undercity. New York: Random House.

Davis, Mike. 2006. Planet of Slums. New York: Verso. 